\title{
Arterial hemodynamics and wave analysis in the frequency and time domains: an evaluation of the paradigms
}

\author{
Alberto Avolio · Berend E. Westerhof • \\ Maria Siebes $\cdot$ John V. Tyberg
}

Received: 19 January 2009/Accepted: 22 January 2009/Published online: 10 February 2009

(C) The Author(s) 2009. This article is published with open access at Springerlink.com

\begin{abstract}
"These laws [of hydraulics] accurately inform us how water will conduct itself under all different circumstances, on account of its gravity, the unconditioned mobility of its parts, and its want of elasticity. Hydrostatics teaches how it is brought to rest through gravity; hydrodynamics, how it is set in motion; and the latter has also to take account of hindrances which adhesion opposes to the will of water: the two together constitute hydraulics."
\end{abstract}

Arthur Schopenhauer

"On the objectification of the will in unconscious nature"

The World as Will and Representation (1819)

Arterial hemodynamics and especially the blood pressure and flow-velocity wave forms have been studied for

\footnotetext{
A. Avolio

Australian School of Advanced Medicine, Macquarie University, North Ryde, Sydney, NSW 2109, Australia

e-mail: alberto.avolio@mq.edu.au

B. E. Westerhof

BMEYE Cardiovascular Monitoring, Suite K2-245, Academic Medical Center, Meibergdreef 9, 1105 AZ Amsterdam,

The Netherlands

e-mail: berend.westerhof@bmeye.com

M. Siebes $(\square)$

Department of Biomedical Engineering and Physics, University of Amsterdam, Academic Medical Center, Meibergdreef 9, 1105 AZ Amsterdam, The Netherlands

e-mail: m.siebes@amc.uva.nl

\section{J. V. Tyberg}

Department of Cardiac Sciences, Libin Cardiovascular Institute of Alberta, University of Calgary, Health Sciences Center, 3330 Hospital Dr. NW, Calgary, AL T2N 4N1, Canada e-mail: jtyberg@ucalgary.ca
}

centuries [9] but their biophysical interpretation is still being debated. A proper biophysical understanding is of paramount importance since it is required for translation to clinical applications. As the title of this Special Issue expresses, an ongoing debate exists between two different paradigms: wave analysis in the frequency and time domains. The aim of this Special Issue is to provide an overview of both paradigms and demonstrate their potential for clinical applications.

One may recognize wave intensity analysis (WIA), introduced by Parker and Jones two decades ago [8], as the most recent and probably most important impetus to the interpretation of arterial hemodynamics and as an alternative to arterial input impedance analysis. However, divergent views in terms of frequency versus time domain analysis have been put forward continually. In a fascinating overview of his career-long personal saga with arterial hemodynamics in this Special Issue [7], Michael O'Rourke sketches the elements of these divergent views that were prevalent half a century ago and still define the present discussion. In view of the apparently regular repetition of the heart beat, is an individual arterial pulse to be considered as a member of a long series of pulses whose characteristics can be described with impressive precision by the powerful mathematical technique of Fourier analysis, or is the arterial pulse to be considered a unique event, mostly unaffected by the history of the preceding pulses? In other words, should the established frequency domain approach, based on the definition of arterial impedance, continue to be pursued by the next generation of investigators, or should some attention shift back to a time domain approach that focuses on the single arterial pulse?

The discussion long ago was a lively one. O'Rourke's mentor, Michael Taylor wrote "... too much attention has 
been paid to the pulse wave as an isolated event, so that the analysis has been in effect aimed at determining the transient response of the arterial system to a single excitation..... A more profitable approach has been made by using Fourier series..." [16]. This view was opposed, initially, as a young O'Rourke "heard gloomy words [from] contemporary authorities in the USA who would not stray beyond analysis of the pulse in the time domain" [7]. He was referring to John Remington who said, "The most major assumption is that the harmonics obtained by a Fourier curve fitting actually exist as separate waves, traveling independently, in the aorta" [12]. To an engineer, such a discussion seems rather theoretical since only the measured pressure and flow signals exist and a Fourier decomposition only predicts, based on assumed linearity, what single, separate harmonics would do. However, for a physiologist or clinician, the disparity between actual waveforms and their Fourier description is apparently more difficult to appreciate.

Frequency and time domain, at least for linear systems, are intrinsically related as has been well recognized by McDonald, who authored a classic monograph with several successor editions that became the "Bible" of arterial hemodynamics [5] and the views of Remington [12] and Peterson [11] have been forgotten. In the introductory comment to his monograph he wrote: “... we occasionally find that new formulations which have been advanced as refutations of earlier ones may, in fact, be essentially the same when analyzed down to their basic components". Despite these sometimes overlooked wise words of caution, the Fourier approach was widely emphasized in physiological and clinical research during the following decades. However, divergent views in terms of frequency versus time domain analysis have been put forward continuously.

The challenge faced by an applied scientist is not so much the discovery of the 'true physical principles' of a physiological system but the development of an understanding that results in a mathematical relation between relevant variables and their determining parameters. The Windkessel model by Westerhof and Noordergraaf is a classical demonstration of this approach [23]. The development of this model is well described in this issue by Nico Westerhof and co-authors [24]. In the time domain, the Windkessel model is characterized in terms of its constitutive differential equations, but it is easily translated into the frequency domain by applying the impedance analogs for such networks comprised of resistance, compliance and inertance. These models have proven very powerful in explaining the pressure-flow relations at the entrance of the arterial system, wave speed via input impedance and form a basic part of practically all textbooks of physiology or biomedical engineering of the circulation.
By definition, a lumped one-compartment Windkessel model lacks the ability of describing the transmission of the pressure wave when it travels in the arterial system. However, as has been recognized rather early [19], transmission line theory applies to elastic tubes and arteries and these elastic systems can be approximated by a series of distributed Windkessel compartments. Such an approach is very powerful and allows the study of geometry and mechanical properties of the branching vascular structure in different vascular beds and animal species of varying body size as demonstrated by Alberto Avolio in this Special Issue [1]. This concept of distributed biophysical properties in the arterial system is further analyzed in this issue by Gary Mitchell in relation to the relevant manifestations of vascular disease [6]. The usefulness of the aortic pressure signal as predictor of diseases related to the arterial system has been further elaborated upon by Mirko De Melis and coauthors [2], who apply a novel approach developed in signal analysis theories based on 'wavelets' (not to be confused with actual hemodynamic waves discussed below). The development of arterial wave mechanics is comprehensively summarized in a historical overview by Kim Parker in this issue [9].

Wave intensity analysis provides a fresh approach to the analysis of waves in elastic tubes and arteries in the time domain and its underlying concepts are well elucidated in this issue by Kim Parker [10]. Waves are considered a succession of wavefronts in terms of incremental changes in pressure and velocity whose superposition results in the waveforms measured at a certain location. The theory is related to a special class of waves known in physics as 'solitary waves', and defines a wave rather differently than used in the Fourier analysis approach since per definition it does not require periodicity. The characteristics of such a wave traveling through an elastic tube are nicely demonstrated in this issue by Jiun-Jr Wang and co-workers [22]. The wave intensity theory has already ignited a series of clinical studies and resulted in a device for analyzing the interaction between the cardiac and arterial system which is discussed by Motoaki Sugawara [14].

Obviously, there must be a relation between different analytical approaches directed at the same biophysical properties of the arterial system. While the different theories may have their respective advantages in application to various phenomena, their predictions must conform to the same reality. Two studies in this issue demonstrate the similarities between the frequency and time domain description of the arterial system: Alun Hughes and Kim Parker consider the forward- and backward-traveling waves in the aorta [3] and Jeroen van den Wijngaard and colleagues in a model of aortic coarctation [18].

It remains that the Windkessel model represents a rather simple approach in understanding the complex features of 
the arterial pressure wave and it dominates, to a large degree, the genesis of the arterial pressure waveform. However, it was not until 2006 that this approach was applied for a similar quantitative analysis of the venous system [21]. It is not easy to reconcile such an elegant but simple Windkessel analysis in the time domain with WIA, but John Tyberg and his co-workers have attempted to do so [20]. In this issue, they propose a model in which measured aortic pressure is considered to be the sum of a Windkessel (a.k.a. reservoir) pressure and a wave-related pressure and where WIA is employed specifically on the wave-related pressure [17]. This approach generates fundamental questions with respect to the energy carried by waves.

Wave intensity analysis has also been applied to the coronary arteries [15], which is highly complicated, since in this circulatory system the waves not only travel from the aorta to the downstream coronary vascular bed but waves are also simultaneously generated by compression of the myocardial microcirculation and travel to the aorta. However, the coronary arteries are short in relation to wavelength which makes this vascular system rather more complicated to analyze than the aorta [4]. Maria Siebes and co-authors discuss some special aspects imposed by the coronary arterial system on the application of wave intensity analysis [13].

As wave intensity analysis is increasingly being applied to different circulatory subsystems, the nomenclature for naming waves has undergone various modifications in attempts to make it more amenable for non-specialists. Forward' and 'backward' always refer to the direction of mean blood flow, although this has also been described as 'proximal originating"' or 'distal originating' relative to the location of the heart. In terms of their effect on pressure, waves were originally classified as 'compression' and 'expansion' waves to describe the resulting increase or decrease in pressure, respectively. This terminology is rooted in gas dynamics and not always intuitive when transposed to hemodynamics in elastic blood vessels. 'Compression-decompression' has been proposed to address this issue. More colloquial terms such as 'pushing_pulling' and 'blowing — sucking' have also been used to illustrate the effect of a wave on the direction of change of pressure. No consensus has been reached yet and the reader will encounter different terminologies in this issue. However, as long as the terminology used is clearly defined, the naming of a wave should not distract from the interpretation of its presence in the context of a particular study.

The guest editors hope that the variety of approaches to interpret arterial, venous, and coronary pressure and flow signals presented in this issue will stimulate the intellectual curiosity in young investigators to examine the complex field of arterial hemodynamics and inspire all relevant disciplines to have a fresh look at the analysis of the cardiovascular system.

Open Access This article is distributed under the terms of the Creative Commons Attribution Noncommercial License which permits any noncommercial use, distribution, and reproduction in any medium, provided the original author(s) and source are credited.

\section{References}

1. Avolio A (2009) Input impedance of distributed arterial structures as used in investigations of underlying concepts in arterial haemodynamics. Med Biol Eng Comput 47. doi:10.1007/s11517008-0413-0

2. De Melis M, Morbiducci U, Rietzschel ER, De Buyzere M, Qasem A, Van Bortel L, Claessens T, Montevecchi FM, Avolio A, Segers P (2009) Blood pressure waveform analysis by means of wavelet transform. Med Biol Eng Comput 47. doi:10.1007/ s11517-008-0397-9

3. Hughes AD, Parker KH (2009) Forward and backward waves in the arterial system: impedance or wave intensity analysis? Med Biol Eng Comput 47. doi:10.1007/s11517-009-0444-1

4. Kolyva C, Spaan JA, Piek JJ, Siebes M (2008) Windkesselness of coronary arteries hampers assessment of human coronary wave speed by single-point technique. Am J Physiol Heart Circ Physiol 295:H482-H490. doi:10.1152/ajpheart.00223.2008

5. McDonald DA (1974) Blood flow in arteries, 2nd edn. Edward Arnold, London

6. Mitchell GF (2009) Clinical achievements of impedance analysis. Med Biol Eng Comput 47. doi:10.1007/s11517-008-0402-3

7. O'Rourke MF (2009) Time domain analysis of the arterial pulse in clinical medicine. Med Biol Eng Comput 47. doi:10.1007/ s11517-008-0370-7

8. Parker KH, Jones CJ (1990) Forward and backward running waves in the arteries: analysis using the method of characteristics. J Biomech Eng 112:322-326. doi:10.1115/1.2891191

9. Parker KH (2009) A brief history of arterial wave mechanics. Med Biol Eng Comput 47. doi:10.1007/s11517-009-0440-5

10. Parker KH (2009) An introduction to wave intensity analysis. Med Biol Eng Comput 47. doi:10.1007/s11517-009-0439-y

11. Peterson LH (1954) The dynamics of pulsatile blood flow. Circ Res 2:127-139

12. Remington JW, O'Brien LJ (1970) Construction of aortic flow pulse from pressure pulse. Am J Physiol 218:437-447

13. Siebes M, Kolyva C, Verhoeff B-J, Piek JJ, Spaan JA (2009) Potential and limitations of wave intensity analysis in coronary arteries. Med Biol Eng Comput 47. doi:10.1007/s11517-0090448-x

14. Sugawara M, Niki K, Ohte N, Okada T, Harada A (2009) Clinical usefulness of wave intensity analysis. Med Biol Eng Comput 47. doi:10.1007/s11517-008-0388-X

15. Sun YH, Anderson TJ, Parker KH, Tyberg JV (2000) Waveintensity analysis: a new approach to coronary hemodynamics. J Appl Physiol 89:1636-1644

16. Taylor MG (1957) An approach to an analysis of the arterial pulse wave. I. Oscillations in an attenuating line. Phys Med Biol 1:258-269

17. Tyberg JV, Davies JE, Wang Z, Whitelaw WA, Flewitt JA, Shrive NG, Francis DP, Hughes AD, Parker K, Wang JJ (2009) Wave intensity analysis and the development of the reservoirwave approach. Med Biol Eng Comput 47. doi:10.1007/ s11517-008-0430-z 
18. van den Wijngaard JP, Siebes M, Westerhof BE (2009) Comparison of arterial waves derived by classical wave separation and wave intensity analysis in a model of aortic coarctation. Med Biol Eng Comput 47. doi:10.1007/s11517-008-0387-y

19. van der Tweel LH (1957) Some physical aspects of blood pressure, pulse wave, and blood pressure measurements. Amer Heart J 53:4-17

20. Wang JJ, O'Brien AB, Shrive NG, Parker KH, Tyberg JV (2003) Time-domain representation of ventricular-arterial coupling as a windkessel and wave system. Am J Physiol Heart Circ Physiol 284:H1358-H1368. doi:10.1152/ajpheart.00175.2002

21. Wang JJ, Flewitt JA, Shrive NG, Parker KH, Tyberg JV (2006) Systemic venous circulation. Waves propagating on a windkessel: relation of arterial and venous windkessels to systemic vascular resistance. Am J Physiol Heart Circ Physiol 290:H154-H162. doi:10.1152/ajpheart.00494.2005

22. Wang JJ, Shrive NG, Parker KH, Tyberg JV (2009) "Wave" as defined by wave intensity analysis. Med Biol Eng Comput 47. doi:10.1007/s11517-008-0403-2

23. Westerhof N, Noordergraaf A (1970) Arterial viscoelasticity: a generalized model. Effect on input impedance and wave travel in the systematic tree. J Biomech 3:357-379

24. Westerhof N, Lankhaar J-W, Westerhof BE (2009) The arterial Windkessel. Med Biol Eng Comput 47. doi:10.1007/s11517008-0359-2 